\title{
A Review Study on Traction Energy Saving of Rail Transport
}

\author{
Xuesong Feng, Hanxiao Zhang, Yong Ding, Zhili Liu, Hongqin Peng, and Bin Xu \\ MOE Key Laboratory for Urban Transportation Complex Systems Theory and Technology, Beijing Jiaotong University, \\ No. 3 Shangyuancun, Haidian District, Beijing 100044, China \\ Correspondence should be addressed to Xuesong Feng; charles.x.feng@gmail.com
}

Received 4 July 2013; Revised 3 August 2013; Accepted 21 August 2013

Academic Editor: Wuhong Wang

Copyright (C) 2013 Xuesong Feng et al. This is an open access article distributed under the Creative Commons Attribution License, which permits unrestricted use, distribution, and reproduction in any medium, provided the original work is properly cited.

\begin{abstract}
The energy cost of a rail transport system is very big especially for the tractions of trains in its daily operation. Continual effort on decreasing the traction energy cost intensities of various rail transport modes has been made by many researchers and practitioners on different aspects for a long time. From the rail transport operation perspective, this study reviews such energy-saving research mainly focusing on the optimizations of train coasting schemes, the rational designs and utilizations of track alignments, the ameliorations of train attributes, and the improvements of system operations. According to the review work, it is confirmed that in sound responses to distinct track alignments, dynamically optimizing control programs of trains with their reasonably improved attributes ought to be further studied in view of the systematic transport operation of a rail line or network in an integrated manner as much as possible in the future research on traction energy saving of rail transport.
\end{abstract}

\section{Introduction}

Although rail is commonly regarded as an energy-saving travel pattern, the operation of a rail transport system consumes in fact a huge amount of energy every day. For example, the weekly electric cost of merely one railway station of Hong Kong Mass Transit Railway Corporation reaches 230 megawatt hours [1]. Such huge energy consumption sometimes may have a serious energy waste. For instance, it is astonishing that the energy cost (EC) per passenger trip of a transport completed by the metro system in New York is even much higher than the EC of the same trip by car on average, mainly due to the low utilizations of the passenger capacities of the metro trains [2].

Therefore, only rationally utilizing a rail transport mode is able to avoid unnecessary EC to achieve its sustainable operation and development. For example, optimizing the streamline design of a train [3], increasing its passenger capacity utilization rate to some reasonable levels $[4,5]$, coasting the train, that is, in other words, taking advantage of its inertia motion, as much as possible in its transport process $[5,6]$, and so on all in practice take much positive effect on decreasing its EC per unit transport. In addition, traction power innovations are also able to not only effectually improve the EC efficiency of a train [7] but also substantially reduce its emissions of $\mathrm{NO}_{x}, \mathrm{CO}, \mathrm{PM}$, and so forth [8].

\section{Energy Cost Factors}

The EC of a rail transport system for its daily operation consists of two parts, that is, the traction EC (TEC) for the tractions of its trains and the additional EC for, for example, lightening in stations, repairing cars in $\operatorname{depot}(\mathrm{s})$, and so forth. The share of the TEC is ordinarily much more than half of the total EC of a rail transport system. As shown in Figure 1, the TEC intensity (i.e., the TEC per unit transport) of a train for its completion of a transport task is dynamically determined by many factors on the aspects of driving tactics (i.e., mainly the coasting program) of the train, alignments (e.g., the slope gradients) of the track, attributes (e.g., the start-stop frequency) of the train, operation management (e.g., the train scheduling) of the rail transport system, natural environment (e.g., the wind [9]) and others (e.g., the aerodynamic forces especially in a tunnel [10]) in an integrated manner.

Focusing on the impacts of various factors, many researchers and practitioners have been continually for a long time making effort for the decrease of the TEC intensity of a train or, afterwards in a further, multitrains operating on 


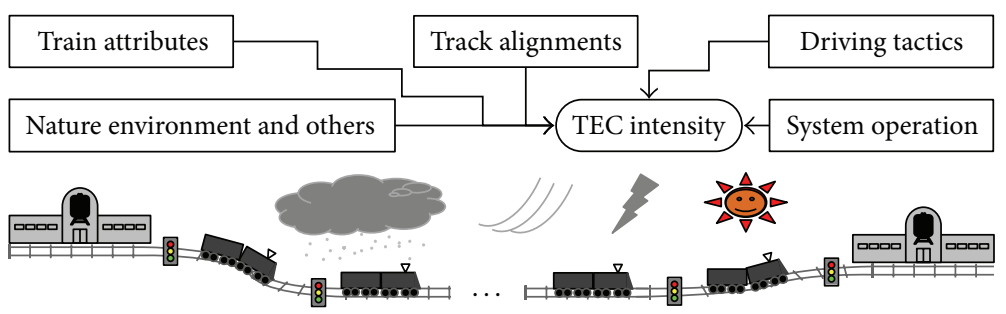

FIGURE 1: Influence on TEC intensity.

a rail transport line or network and have proposed many valuable suggestions. This study reviews these works from the transport operation perspective mainly with respect to train coasting control optimization, reasonable track alignment design and utilization, train attribute amelioration, and rail transport system operation management improvement. Accordingly, the direction of our effort in future research is indicated for radically decreasing the TEC intensity of the rail transport system operation in an effective way.

\section{Coasting Control}

A train consumes energy in a relatively very slight intensity when it coasts. Rational site choices of a train for the starts of its coasting along a rail line are able to effectively decrease the TEC of the train for its whole trip by avoiding its brakes for changing its speed with much loss of its kinetic energy. As illustrated in Figure 2, much importance in research has been attached to the optimization of the coasting scheme of a train for its energy saving in regard to transport time expenditure (TTE), train traction performance, passenger ride comfort, and so forth.

Based on train traction calculations [11, 12], a transport simulation program following the principle of coasting vector (i.e., coasting speed and coasting start point) to achieve the optimum automatic train operation with the least TEC for a trip in a certain travel time is developed by Chui et al. [13] for Kowloon-Canton Railway (KCR). A train is given a coasting vector data from the trackside so that whenever the train has actually reached the coasting speeds or coasting start points determined with a view to passenger travel demands in different daily operation time of a rail line, its motoring power will be shut off. In this way, about $3 \%$ of the TEC could be saved for KCR.

For the sake of improving the application result veracity of a train coasting program, Chang and Sim [14] newly propose a genetic algorithm (GA) [15] applied in their rail transport simulation study which takes moving block signals [16] to insure the safe distance between two neighboring trains running on the same rail line. Different sites of a transport section between neighboring stops and various control actions of a train are respectively regarded as genes and chromosomes in the GA to search for the optimal coasting start points of the train. Decreasing TEC, ensuring on-time running, and avoiding jerky actions (i.e., in other words, providing comfortable transport service to the passengers) of a train are

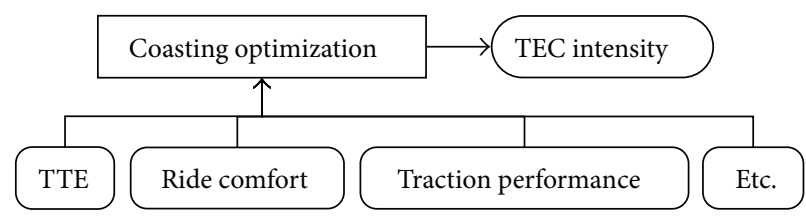

FIGURE 2: Coasting optimization for decreasing TEC intensity.

considered in a comprehensive way to optimize its driving tactics for a transport mission.

Because of the computational complexities of GAs for the exploration of the optimal coasting program in comparison with, for example, gradient algorithms [17] especially when the stop spacing of a train is comparatively very short [18], Hwang [19] tries to simplify the process of optimizing coasting controls of a high-speed railway (HSR) train for its energy saving. The relationships between the economic speed of a HSR train and its TEC and TTE for a passenger transport work are built based on fuzzy clustering analyses [20,21]. As a result, it is possible to get the range of the economic speed of a train according to expected TEC and TTE. Thereafter, the coasting program of a train is resolved by taking advantage of a hybrid scheme of GAs to optimize the speeds of the train at different rail sites within its economic speed range.

Due to low efficiencies of classic numerical optimization methods [22] and burdensome train traction calculations in detailed simulations of the transport controls of a train [5], it is difficult to truly realize the optimum on-board controls for the minimal TEC. On the basis of existing studies, Bai et al. [23] develop a set of train operation guidance equipments to successively give suggestions to the driver of a train in its transport process for optimizing the driving actions for traction energy saving to some dynamically real-time extent. Liu and Golovitcher [22] provide an analytical approach solved by maximum principles $[24,25]$ for relatively efficient decisions of optimal control change points of a train adopting full or partial braking, coasting, or motoring with partial or full power. Moreover, according to the statistical distribution of the operating conditions described by the speeds and accelerations of a train on the macrolevel, Lindgreen and Sorenson [5] simplify the transport simulation work for the versatile and flexible control strategy (including coasting start points) optimization with an acceptable TEC computation accuracy.

Based on previous research on the effect of optimizing the coasting plan of a train on its TEC intensity, analyses of 
the additional impacts of traction acceleration and braking capacity of a train are made by Bocharnikov et al. [26] in simulation with utilizing dynamics theories [27], GAs, and fuzzy mathematics (FM) [28]. Different coasting programs of a train for the same transport work are comparatively studied with focusing on the changes of its TTE as well as TEC. The coasting scheme is finally determined to prevent the unilateral optimization of the TEC at overmuch expense of the TTE. The utilized GA is able to effectively avoid improperly adopting local optimal solutions in searching for the most energy-saving coasting start points for the whole trip. Moreover, variables applied in the dynamic simulations are well defined by FM methods.

With regard to transport time schedule adherence, Kim and Chien [29] newly develop a train performance simulation approach to optimize the controls of a train for distinct types of track alignments to decrease its TEC for a certain trip. Under some transport time constraints for a transport distance between neighboring stops, the most energy-saving control scheme of a train for the transport section is determined according to the optimal selection of its coasting start points. In this respect, simulated annealing approach [30] is utilized to analyze the TECs of different operations of the train for various track alignments in the transport section which is divided into many small subsections. Further, Kim and Chien [31] improve their work with the additional consideration of the formation of a train. The sensitivity analyses of different factors such as track alignment, speed limit and train formation of a train are also made for its energy saving.

\section{Track Alignments}

As previously-clarified from the viewpoint of optimizing the coasting scheme of a train, various types of track alignments have different influence upon the TEC intensity of the same train control action. Therefore, by effectively transforming potential energy of ramps along a rail line [32-34] and increasing running straightness of a train in plane [35], reasonable designs and/or utilizations of the track alignments are much beneficial to reducing the TEC intensity of a train. Valuable studies have been made on this aspect in view of, for example, driving strategy of a train, headway of trains, and ride comfort of passengers, as interpreted in Figure 3.

Focusing on updating the ramps in stations along a metro line for different transport distances between neighboring stops, Hoang et al. [36] first attempt to simultaneously optimize vertical track alignments and train operation control for traction energy saving. Different patterns of the ramps are defined according to realities. Heuristic algorithms [37] and dynamic programming (DP) [38] are used to detect the slope change points of each type of the ramps. Thereafter, a simulation approach is applied in accordance with the principles of train traction calculations to compute the TEC of a train for its trip from one terminal station to another of a rail line. The designs of the energy-saving slopes of the ramps in each of the stations and the corresponding actions of a train on different rail sites are able to be optimized rationally.

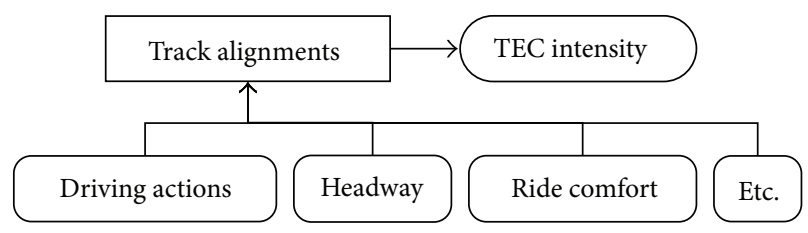

FIgURE 3: Track alignment design and utilization for reducing TEC waste.

From a unique viewpoint, Firpo and Savio [39] do research on how to reduce the electric energy provided by a transformer substation to a transport section of an HSR line for the transports of a certain number of trains within some time. The impacts of the track alignments together with the site of the transformer substation along the rail line and the headway of the trains in the transport section on the electricity supplied by the transformer substation are studied comprehensively. With the help of electromechanical system modeling approach [40], the established nonlinear optimization model is solved by both Simplex method [41] and stochastic hill-climbing algorithm $[42,43]$ to explore the optimal combination of target speed, acceleration, and time in stop of a train for the transport section.

On the assumption that the climbing ability of a metro train is capable of coping with all kinds of ramps, Kim and Schonfeld [44] study simulation of the influence of various types of vertical track alignments upon the intensities of both TEC and TTE of the train in consideration of the ride comfort requirements of the passengers. It is concluded that if a stop spacing is shorter than about 2,400 meters, a rational slope design of a ramp in station is able to take obviously positive effect on saving the TEC of a train for this stop spacing mainly because of its coasting after the ramp. Moreover, reducing the acceleration of a train is of benefit to decrease its TEC for the same transport work, but meanwhile, its TTE increases in correspondence.

Regarding impacts of different radians of various types of track curves in plane on the TEC intensity of a train, Liu et al. [35] make simulation analyses with employing train traction calculations. It is demonstrated that the increase of the TEC intensity of a metro train with the decrease of the track curve radius is obviously accelerated when the curve radius becomes smaller than about 300 meters. In contrast, if radiuses of track curves are over approximately 500 meters, their radians have almost no influence upon the TEC intensity of a metro train.

It is true that the speed adjustment action of the driver is lagged behind the change of the speed (control reminding) code of a train when the track gradient, speed restriction, and so forth are various between successive stops. As a result, Ke et al. [45] propose a combinatorial optimization model to minimize the TECs of a train for each of its transport sections. A MAX-MIN ant system [46] is used to optimize the train-speed trajectory for reducing the computational burden on the block-layout design. Further, the optimal speed codes of a train are also determinable for its transport in different sections to provide an energy-saving, efficient, and 
comfortable service [47]. In order to insure the practicability of corresponding driving strategies, the relationships between the acceleration and speed of the train and the track gradient are regulated with a fuzzy process $[48,49]$ to reflect the correlations among track alignments, train actions, and corresponding TECs.

\section{Train Attributes}

Besides the optimum driving controls of a train and the rational designs and utilizations of track alignments, ameliorated attributes of a train also play important roles in its traction energy saving. Different from the viewpoints of aforementioned studies, many works pay much attention to for example, motor flux, weight, mass distribution, electricity supply effectiveness, traction power output, startup-stop frequency, formation, carrying capacity utilization rate, and so forth of a train for the improvement of its TEC efficiency. As shown in Figure 4, such research involves different fields including electrical control, rail car manufacturing, rail transport operation management, mechanics, and electric power supply.

From the perspective of regenerative braking of a train, Kokotovic and Singh [50] as early as in the 1970s have proposed an optimization approach to provide the basis for the improvement of train control circuit through optimizing the electric motor flux control to reduce the energy cost intensity of the traction motor of a train. With referring to the correlations between the speeds and traction forces of a train for different track alignments [11], the energysaving transport objective of the train is achieved by utilizing a Hamiltonian system [51] with adjoint analyses [52] to rationally adjust the speed of the train through traction motor flux control. In addition, the relationship between the TEC and TTE of the train is also studied with the application of Green's theorem [53] for further optimization of the motor flux control.

According to train traction calculations applied in simulations of the transport procedures of different types of Chinese metro trains, it is empirically confirmed that the TEC intensity of a metro train in China is increased with raising its weight in an approximately linear way [35]. Reducing the weight of a train is a direct means to decrease its TEC intensity through reducing the resistances to the train in its trip. On the basis of the detailed survey on various technical specifications of different types of trains in Germany, IFEU [54] analyzes the general energy-saving effect of reducing $10 \%$ of the weight of each type of the trains. It is revealed that the vast majority of the TEC of an urban or regional rail transit train for its whole trip is used to accelerate the train in its startups because of its comparatively very short stop spacing on average. As a result, if the weight of such a train decreases by $10 \%$, it is able to save about $7 \%$ or $8 \%$ of its TEC for a trip in Germany. In comparison, an intercity train with a relatively long stop spacing needs to spend roughly half of its TEC in overcoming the air resistance to its moving after a startup, and therefore, the TEC saving by lighting the weight of the train is from $4 \%$ to $5 \%$.

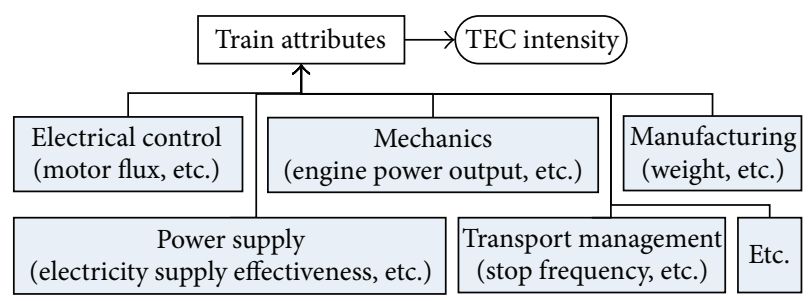

FIgURE 4: Attribute improvement for TEC intensity reduction.

As for simulation research on rail transports, initially a mass point or afterward a line with its mass evenly distributed is commonly used to roughly represent a train. In contrast, Chou and Xia [55] analyze the impact of the mass difference of various parts of a freight train on the TEC and TTE of its whole trip with regard to transport security. In their simulation work, a heavy haul train is divided into a certain number of units according to the traction power distribution of the train. Every two neighboring units is separated with protective equipments controlled by electric signals in an associated way to dynamically adjust actions of different units confronted with different track alignments. Optimal control strategies to reduce the TEC and TTE of a transport and improve its security are suggested on the basis of the simulation analyses.

For the purpose of decreasing the TEC intensity of a diesel multiple-unit train, Lu et al. [56] evaluate different combinations of the traction power outputs from the multiengines of the train for a certain total traction power output. DP has been applied to analyze the TECs produced by a single-train motion simulator to identify the global optimal program of the traction power distribution between different engines of a train for a certain transport whose profile must be obtained in advance. To realize the online power management [57], an adaptive online strategy for the realtime optimization based on the results from the DP study is put forward. It is indicated that the optimized solution has a TEC reduction of around 7\% in comparison with even distribution of the total traction power output of a train to each of its engines for the same transport mission.

A high startup stop or accelerating-braking frequency of a train substantially increases its TEC for the same transport task $[5,6]$. For example, an express train running without any stops from Copenhagen to Elsinore is able to save about $50 \%$ of its TEC in comparison with its transport with every stop for this trip [5]. Feng [58] and Feng et al. [59], respectively, prove that the increase of the TEC intensity of an HSR or metro train with shortening the stop spacing is apparently accelerated when the stop spacing becomes shorter than correspondingly around 100 kilometers or 1,800 meters, and such a trend becomes more obvious if the target speed of the train is improved. In consideration of short distances between neighboring stations of most metro lines in reality, a relatively low target speed of a metro train $[35,59]$ and its frequent coasting operations are able to effectively decrease its TEC intensity $[6,60]$ especially for relatively low boarding rates in off-peak hours when the TEC intensity of the metro system 
is much further decreased if the trains extend their headways [13].

As widely recognized, it is comparatively easier to make the utilization rates of the passenger capacities of shortly formed trains relatively high according to dynamically changed travel demands of the passengers, which will obviously decrease the total TEC intensity of the trains running on a rail line or network [31]. Moreover, the decrease of traction power of a train is able to reduce its TEC intensity with more TTE $[26,44]$. In addition, Feng et al. [61] also reveal that in comparison with the TEC of a short HSR train with the same equipments, an HSR train with a long formation may have more TEC for the same trip due to the speed restrictions of the exit switches of the tracks in stations. All these facts require systematically reasonable and flexible applications of trains with different formation lengths and traction capacities in view of detailed passenger travel demands in different operation times or seasons of a rail transport system.

\section{System Operation}

The sustainable as well as efficient operation of a rail transport system is supported by not only superior performance of its equipment and facilities but also rational system operation management. However, because of, for example, spatially uneven transport demands as a whole, only aggregate statistics on the overall TEC intensity is unable to reflect the demand variety at different parts of a rail transport system [62] and certainly hard to provide adequately effective energy-saving approaches in systematic concepts. Taking into account interactions, timetable adherences, and so forth of multitrains operating on the same rail line or network, research on minimizing their total TEC, especially in recent years, makes much effort to get solutions from the perspective of systematic operation, as explained in Figure 5. This kind of research is able to reasonably contribute to decreasing the overall TEC intensity of a rail transport system.

Kraay et al. [63] and Higgins et al. [64] have tried to optimize the train operation diagram by utilizing mathematical programming to adjust the speeds and priorities of trains in an integrated manner for reducing their delays and total TEC. In view of the transport characteristics of the trains operating on the railway network of China in reality, Peng et al. [65] establish a schedule optimization model with the multiobjectives of optimal or near optimum total TTE and TEC of trains. The practicability and adaptability of the proposed model for complex network structure are guaranteed, and a decomposition algorithm is put forward to solve this model. In consideration of both structure complexity of a rail network and difference of passenger carrying capacities of different types of trains, Ghoseiri et al. [66] propose a new train scheduling model with more objectives besides decreasing the total TEC and TTE of trains, and the Pareto optimality [67] is suggested to be used to solve the model.

To reduce the TEC of a rail transport system and meanwhile maintain a certain service quality, dwell times of trains at stations or/and their interstop TTEs need dynamic

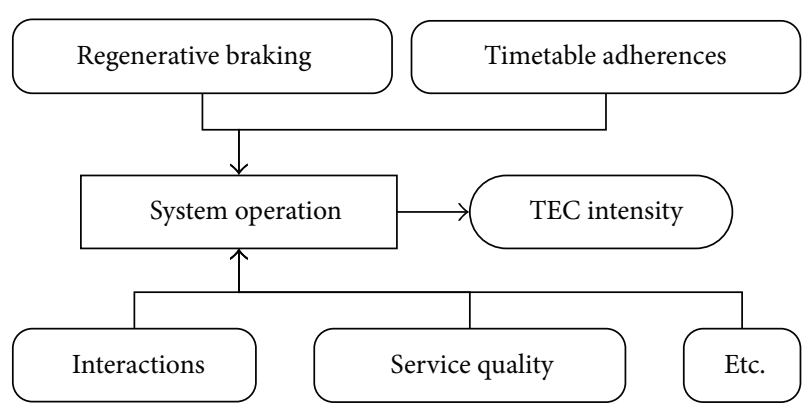

FIGURE 5: Rationally systematic operation for TEC saving.

adjustments to match time-varying travel demand. The dwell time adjustment is commonly utilized owing to its simplicity in practice [68]. For instance, a Heuristic-based train operation controller has been developed by Sansò and Girard [69] to reduce the power demand of a metro system in peak hours by introducing optimal dwell times for trains at successive stations. Because adjusting the interstop TTEs of a train with coasting controls can easily realize the exchange between its TEC and TTE for a whole trip [70], Wong and Ho [68] apply DP based on an event-based model to rationally optimize the interstop TTEs of metro trains according to dynamically changed passenger travel demand over a regional level especially in off-peak hours for energy saving under the premise of ensuring a certain level of the transport service.

If trains running on different rail lines are approaching the same transport section, the green wave strategy [71] for reducing their brakes and stops before entering the conflicting section is able to effectively decrease the TECs of these trains for their transports [72]. In order to make trains run through a conflicting transport section in the smoothest way, Bai et al. [73] apply golden section search method [74] to determine the most suitable speeds of trains when they are approaching a conflicting section. In comparison with the maximum traction strategy with the principle of improving the speed of a train before running into a conflicting transport section to its target speeds as much as possible, the proposed approach may save about $6 \%$ of the TEC of such a train. Moreover, Fu et al. [75] make use of a GA with changeable lengths of chromosomes to analyze the interimpacts of different trains passing through the same stop from different directions at nearly the same time. According to the analyzed inter-impacts, corresponding energy-saving train control rules are suggested.

In an integrated electricity supply viewpoint, Falvo et al. [76] study the energy-saving effect of regenerative braking [77] of metro trains running on a rail network. The utilizations of the electricity provided by the traction electric power supply system and the electric energy from the regenerative braking of metro trains for the tractions of trains on the same metro network are recorded in the simulation study of the transport operations of these trains. Regenerative braking enables much energy saving by not only injecting part of the braking kinetic energy of a train into the electrical grid to be consumed by nearby powering trains or returned to the AC 
transmission system through a reversible substation [78] but also preventing the tunnel temperature rising in underground railways [79] to minimize the energy consumption in air conditioning or ventilating. The average utilization rate of the regenerative electric power for train tractions decreases with increasing the headways of multitrains even if all of them are equipped with electrical energy storage devices such as the flywheel system [80], and a train must activate the rheostatic braking to burn some regenerated power when the catenary voltage has reached its top limit [78]. The unused regenerative electric power for train traction is suggested to serve other electricity consumption systems, for example, electric vehicle charging stations in urban area, especially when the headways of the trains are relatively big.

In consideration of the interactions of trains in their following transports on the same rail line, Ding et al. [81] establish a dynamics model to optimize the energysaving driving controls of following trains influenced by the dynamically changes of rail transport signals, according to their previously proposed simulation algorithm [82] for the energy-saving control of a single train under its fixed travel time constraint for a certain transport. The corresponding Heuristic algorithm is also proposed to estimate the dynamics model. Based on this model, the computer-aided simulation system is developed to get the optimal TEC of train following operation under the automatic block system [16]. This dynamics modeling research is capable of optimizing the controls of following trains according to the signals to avoid unnecessary brakes for adjusting their speeds. As a result, the TEC of such trains is decreased. Additionally, taking into account the energy saving effect of regenerative braking, Acikbas and Soylemez [83] make use of artificial neural networks $[84,85]$ to develop the simulation system taking a GA to search for systematically rational coasting start points of different trains. In a different manner, Yang et al. [86] first establish the penalty function to evaluate the influence of the interactions of trains upon their TTEs and TECs. Afterwards, the weight values of the overall TTE and TEC for an integrated cost evaluation are obtained by spreadsheet analyses. At last, a GA is accordingly utilized to explore the optimal control program in a systematic way.

Because of the uncertain delays of trains due to the interinfluence of their transports on the same rail line or network, Ding et al. [87] and Cucala et al. [88] combine coasting program optimization and transport schedule modeling [89, 90] to minimize the TEC of multitrains. In the transport simulation study, a GA is applied to explore energy-saving coasting schemes of the trains and obtain the relationship between the corresponding TEC and TTE of each scheme. In order to realize the least TEC for the trains resuming a transport time schedule in case of an uncertain delay, Ding et al. [87] distribute the slack travel time of the rail line to each of its transport sections simply according to the previously obtained relationship between the TEC and the TTE mainly in view of the track alignments in all the transport sections and the length of every stopspacing. In contrast, based on the relationship between the TEC and the TTE, the fuzzy linear programming [91] is utilized by Cucala et al. [88] to rationally make use of the slack time of a rail line for the delays which are modeled as fuzzy numbers and punctuality constraints and capable of getting reasonable behavioral responses of the drivers for the most effective decrease of the general TEC. Such an approach is also applied to some Spanish HSR lines to evaluate the energy-saving potential of its commercial transport service.

In view of the TECs and carbon emissions of trains and the TTEs of their passengers, Li et al. [92] recently develop a green train scheduling model to optimize the transport timetable of multitrains in the operation of a rail transport system for the reduction of the system cost. The TEC of each train is determined according to the correlations between its running resistance, speed, and TTE for a transport work. The carbon emission cost of all the trains is computed based on their allowed and actual emission volumes. The total TTE of the passengers is used to describe the travel demand in a certain time period. This multiobjective nonlinear optimization problem is solved with the utilization of fuzzy mathematical programming [91]. It is proved that taking into account the TTE of all the passengers of multitrains operating on the same rail line or network, the newly developed model is able to effectively decrease the TEC and carbon emission of the systematic transport operation.

\section{Summary}

There is no doubt that as to the driving strategy optimization on the microlevel, a rational control program, especially a valid coasting scheme, of a train enables an evident decrease of its TEC for the same transport work. As a result, many studies have been made to explore reasonable approaches that are able to efficiently determine in particular the optimal coasting start points of a train in detail for its certain trip to ultimately realize dynamic optimization of its driving tactics on board for energy saving. Meanwhile, impacts of various types of track alignments on the TEC intensity of a train need adequate analyses in its operating control optimization. Moreover, it is also clarified on the mesolevel that the ameliorative attributes such as reduced weight, improved power output efficiency, decreased accelerating-braking frequency, and so forth of a train all play important roles in decreasing the TEC of the whole transport operation process of the train. Furthermore, from the perspective of the transport organization on the macrolevel, the interinfluence of multitrains in their coordinate operations requires systematic solutions to radically decrease the overall TEC intensity of a rail transport system in an effective manner.

In view of both instability of a system when its behavior influenced by multifactors changes seriously [93] and the systematic characteristics of the transport operation of a rail line or network, dynamically systematical optimization of the control programs of trains with reasonably amendatory attributes in sound responses to track alignments is necessary to be further studied in an integrated way as much as possible in future research on traction energy saving of rail transport. This is also much beneficial to the improvement of rail transport safety $[94,95]$. Of course, utilizing new energy, for 
example, hydrogen against electrification [96, 97], deserves our continual effort as well.

\section{Acknowledgments}

This research is supported by the National Natural Science Foundation of China (71201006 and 71131001), the National Basic Research Program of China (2012CB725406) and the Fundamental Research Funds for the Central Universities (2011JBM251).

\section{References}

[1] P. C. M. Leung and E. W. M. Lee, "Estimation of electrical power consumption in subway station design by intelligent approach," Applied Energy, vol. 101, pp. 634-643, 2013.

[2] C. Winston and V. Maheshri, "On the social desirability of urban rail transit systems," Journal of Urban Economics, vol. 62, no. 2, pp. 362-382, 2007.

[3] J. Hickman, D. Hassel, R. Joumard, Z. Samaras, and S. Sorenson, Methodology for Calculating Transport Emissions and Energy Consumption, Office for Official Publications of the European Communities, Luxembourg, Belgium, 1999.

[4] X. Feng, "Energy cost of high-speed railway trains in the effect of utilization ratios of passenger seats," in Proceedings of the International Conference on Information, Services and Management Engineering (ISME '11), vol. 1, pp. 133-136, Beijing, China, December 2011.

[5] E. Lindgreen and S. C. Sorenson, Simulation of Energy Consumption and Emissions from Rail Traffic Evaluation, Technical University of Denmark, Lyngby, Denmark, 2005.

[6] P. Lukaszewicz, Energy consumption and running time for trains: modelling of running resistance and driver behavior based on full scale testing [Ph.D. thesis], Royal Institute of Technology, Stockholm, Sweden, 2001.

[7] A. R. Miller, J. Peters, B. E. Smith, and O. A. Velev, "Analysis of fuel cell hybrid locomotives," Journal of Power Sources, vol. 157, no. 2, pp. 855-861, 2006.

[8] H. Wang, H. Hao, X. Li, K. Zhang, and M. Ouyang, "Performance of Euro III common rail heavy duty diesel engine fueled with gas to liquid," Applied Energy, vol. 86, no. 10, pp. 2257-2261, 2009.

[9] E. V. Hoyt and R. R. Levary, "Assessing the effects of several variables on freight train fuel consumption and performance using a train performance simulator," Transportation Research A, vol. 24, no. 2, pp. 99-112, 1990.

[10] R. S. Raghunathan, H. D. Kim, and T. Setoguchi, "Aerodynamics of high-speed railway train," Progress in Aerospace Sciences, vol. 38, no. 6-7, pp. 469-514, 2002.

[11] H. I. Andrews, Railway Traction: The Principles of Mechanical and Electrical Railway Traction, vol. 5 of Studies in Mechanical Engineering, Elsevier Scientific, New York, NY, USA, 1986.

[12] C. Chandra and M. M. Aqarwal, Railway Engineering, Oxford Higher Education, New York, NY, USA, 2008.

[13] A. Chui, K. K. Li, and P. K. Lau, "Traction energy management in KCR," in Proceedings of the 2nd International Conference on Advances in Power System Control, Operation \& Management, vol. 1, pp. 202-208, December 1993.
[14] C. S. Chang and S. S. Sim, "Optimising train movements through coast control using genetic algorithms," IEE Proceedings-Electric Power Application, vol. 144, no. 1, pp. 65-73, 1997.

[15] J. S. Arora, "Genetic algorithms for optimum design," in Introduction to Optimum Design, J. S. Arora, Ed., pp. 643-655, Academic Press, Waltham, UK, 3rd edition, 2012.

[16] B. Solomon, Railroad Signaling, Voyageur Press, Minneapolis, Minn, USA, 2010.

[17] T. H. Cormen, C. E. Leiserson, R. L. Rivest, and C. Stein, Introduction to Algorithms, MIT Press, Cambridge, Mass, USA, 3rd edition, 2009.

[18] K. K. Wong and T. K. Ho, "Coast control for mass rapid transit railways with searching methods," IEE Proceedings: Electric Power Applications, vol. 151, no. 3, pp. 365-375, 2004.

[19] H. Hwang, "Control strategy for optimal compromise between trip time and energy consumption in a high-speed railway," IEEE Transactions on Systems, Man, and Cybernetics A, vol. 28, no. 6, pp. 791-802, 1998.

[20] F. Hppner, F. Klawonn, K. Kruse, and T. Runkler, Fuzzy Cluster Analysis: Methods for Classification, Data Analysis and Image Recognition, John Wiley \& Sons, Chichester, UK, 1999.

[21] M. S. Yang, "A survey of fuzzy clustering," Mathematical and Computer Modelling, vol. 18, no. 11, pp. 1-16, 1993.

[22] R. Liu and I. M. Golovitcher, "Energy-efficient operation of rail vehicles," Transportation Research A, vol. 37, no. 10, pp. 917-932, 2003.

[23] Y. Bai, B. Mao, Y. Ding, F. Zhou, and W. Jia, "An onboard optimal control system for freight trains," in Proceedings of the 6th International Conference on Traffic and Transportation Studies Congress, pp. 770-783, Nanning, China, August 2008.

[24] A. Ioffe and V. Tikhomirov, Theory of External Problems, Nauka, Moscow, Russia, 1974.

[25] R. E. Showalter, "The maximum principle," in Introduction to Holomorphy, J. A. Barroso, Ed., vol. 106 of North-Holland Mathematics Studies, chapter 10, pp. 115-117, Elsevier Science B.V., Amsterdam, The Netherlands, 1985.

[26] Y. V. Bocharnikov, A. M. Tobias, C. Roberts, S. Hillmansen, and C. J. Goodman, "Optimal driving strategy for traction energy saving on DC suburban railways," IET Electric Power Applications, vol. 1, no. 5, pp. 675-682, 2007.

[27] T. R. Kane and D. A. Levinson, Dynamics: Theory and Applications, McGraw-Hill, New York, NY, USA, 1985.

[28] J. N. Mordeson, "Fuzzy mathematics," in Foundations of Image Understanding, L. S. Davis, Ed., pp. 95-126, Springer Science, Business Media, New York, NY, USA, 2001.

[29] K. Kim and S. I. Chien, "Simulation-based analysis of train controls under various track alignments," Journal of Transportation Engineering, vol. 136, no. 11, pp. 937-948, 2010.

[30] D. Bertsimas and J. Tsitsiklis, "Simulated annealing," Statistical Science, vol. 8, no. 1, pp. 10-15, 1993.

[31] K. Kim and S. I. Chien, "Optimal train operation for minimum energy consumption considering track alignment, speed limit, and schedule adherence," Journal of Transportation Engineering, vol. 137, no. 9, pp. 665-674, 2011.

[32] G. F. Ignacio and G. A. Alberto, "Can high-speed trains run faster and reduce energy consumption," Procedia-Social and Behavioral Sciences, vol. 48, pp. 827-837, 2012.

[33] P. Howlett, “The optimal control of a train," Annals of Operations Research, vol. 98, no. 1-4, pp. 65-87, 2000. 
[34] P. G. Howlett, P. J. Pudney, and X. Vu, "Local energy minimization in optimal train control," Automatica, vol. 45, no. 11, pp. 2692-2698, 2009.

[35] H. Liu, B. Mao, Y. Ding, W. Jia, and S. Lai, "Train energysaving scheme with evaluation in urban mass transit systems," Journal of Transportation Systems Engineering and Information Technology, vol. 7, no. 5, pp. 68-73, 2007.

[36] H. H. Hoang, M. P. Polis, and A. Haurie, "Reducing energy consumption through trajectory optimization for a metro network," IEEE Transactions on Automatic Control, vol. 20, no. 5, pp. 590-595, 1975.

[37] S. Edelkamp and S. Schrdl, Heuristic Search: Theory and Applications, Morgon Kaulfmann, Waltham, Mass, USA, 2011.

[38] E. V. Denardo, Dynamic Programming: Models and Applications, Dover, New York, NY, USA, 2003.

[39] P. Firpo and S. Savio, "Optimized train running curve for electrical energy saving in autotransformer supplied AC railway systems," in Proceedings of the International Conference on Electric Railways in a United Europe, pp. 23-27, Amsterdam, The Netherlands, March 1995.

[40] S. E. Lyshevski, Electromechanical Systems, Electric Machines, and Applied Mechatronics, CRC Press, Boca Raton, Fla, USA, 1999.

[41] I. Maros, Computational Techniques of the Simplex Method, Kluwer Academic, Dordrecht, The Netherlands, 2002.

[42] D. A. Coley, An Introduction to Genetic Algorithms for Scientists and Engineers, World Scientific, Singapore, 1999.

[43] A. W. Johnson and S. H. Jacobson, "On the convergence of generalized hill climbing algorithms," Discrete Applied Mathematics, vol. 119, no. 1-2, pp. 37-57, 2002.

[44] D. N. Kim and P. M. Schonfeld, "Benefits of dipped vertical alignments for rail transit routes," Journal of Transportation Engineering, vol. 123, no. 1, pp. 20-27, 1997.

[45] B. R. Ke, M. C. Chen, and C. L. Lin, "Block-layout design using maxmin ant system for saving energy on mass rapid transit systems," IEEE Transactions on Intelligent Transportation Systems, vol. 10, no. 2, pp. 226-235, 2009.

[46] T. Stützle and H. H. Hoos, "MAX-MIN ant system," Future Generation Computer Systems, vol. 16, no. 8, pp. 889-914, 2000.

[47] B. R. Ke, C. L. Lin, and C. W. Lai, "Optimization of train-speed trajectory and control for mass rapid transit systems," Control Engineering Practice, vol. 19, no. 7, pp. 675-687, 2011.

[48] B. Liu, "Fuzzy process, hybrid process and uncertain process," Journal of Uncertain Systems, vol. 2, no. 1, pp. 3-16, 2008.

[49] K. M. Passino and S. Yurkovich, Fuzzy Control, Addison-Wesley, Longman, Menlo Park, Calif, USA, 1998.

[50] K. P. Kokotovic and S. G. Singh, "Minimum-energy control of a traction motor," IEEE Transactions on Automatic Control, vol. 17, no. 1, pp. 92-95, 1972.

[51] A. Blokhuis, "Hamiltonian systems," in Methods of Differential Geometry in Analytical Mechanics, M. Len and P. R. Rodrigues, Eds., vol. 158 of North-Holland Mathematics Studies, chapter 6, pp. 263-299, Elsevier Science B.V., Amsterdam, The Netherlands, 1989.

[52] R. H. Martin and M. Pierre, "The adjoint operator method," in Computational Methods in Engineering Boundary Value Problems, T. Y. Na, Ed., vol. 145 of Mathematics in Science and Engineering, chapter 4, pp. 52-69, Academic Press, New York, NY, USA, 1979.
[53] A. Miele, "Extremization of linear integrals by green's theorem," in Optimization Techniques with Applications to Aerospace Systems, G. Leitmann, Ed., vol. 5 of Mathematics in Science and Engineering, pp. 69-98, Academic Press, New York, NY, USA, 1962.

[54] IFEU (Institut für Energieund Umweltforschung Heidelberg $\mathrm{GmbH}$ ), Energy Savings by Light-Weighting (Final Report), International Aluminium Institute (IAI), Heidelberg, Germany, 2003.

[55] M. Chou and X. Xia, "Optimal cruise control of heavy-haul trains equipped with electronically controlled pneumatic brake systems," Control Engineering Practice, vol. 15, no. 5, pp. 511-519, 2007.

[56] S. Lu, S. Hillmansen, and C. Roberts, "A power-management strategy for multiple-unit railroad vehicles," IEEE Transactions on Vehicular Technology, vol. 60, no. 2, pp. 406-420, 2011.

[57] Y. Zhu, Y. Chen, G. Tian, H. Wu, and Q. Chen, "A four-step method to design an energy management strategy for hybrid vehicles," in Proceedings of the American Control Conference (AAC '04), pp. 156-161, Boston, Mass, USA, July 2004.

[58] X. Feng, "Optimization of target speeds of high-speed railway trains for traction energy saving and transport efficiency improvement," Energy Policy, vol. 39, no. 12, pp. 7658-7665, 2011.

[59] X. Feng, B. Mao, X. Feng, and J. Feng, "Study on the maximum operation speeds of metro trains for energy saving as well as transport efficiency improvement," Energy, vol. 36, no. 11, pp. 6577-6582, 2011.

[60] R. A. Uher, N. Sathi, and A. Sathi, "Traction energy cost reduction of the WMATA metro rail system," IEEE Transactions on Industry Applications, vol. IA-20, no. 3, pp. 472-483, 1984.

[61] X. Feng, J. Feng, K. Wu, H. Liu, and Q. Sun, "Evaluating target speeds of passenger trains in China for energy saving in the effect of different formation scales and traction capacities," International Journal of Electrical Power and Energy Systems, vol. 42, no. 1, pp. 621-626, 2012.

[62] I. López, J. Rodríguez, J. M. Burón, and A. García, "A methodology for evaluating environmental impacts of railway freight transportation policies," Energy Policy, vol. 37, no. 12, pp. 5393$5398,2009$.

[63] D. Kraay, P. T. Harker, and B. Chen, "Optimal pacing of trains in freight railroads: model formulation and solution," Operations Research, vol. 39, no. 1, pp. 82-99, 1991.

[64] A. Higgins, E. Kozan, and L. Ferreira, "Optimal scheduling of trains on a single line track," Transportation Research B, vol. 30, no. 2, pp. 147-161, 1996.

[65] Q. Peng, S. Zhu, and P. Wang, "Study on the strategy of train operation adjustment on high speed railway," Journal of the China Railway Society, vol. 23, no. 1, pp. 1-8, 2001.

[66] K. Ghoseiri, F. Szidarovszky, and M. J. Asgharpour, "A multiobjective train scheduling model and solution," Transportation Research B, vol. 38, no. 10, pp. 927-952, 2004.

[67] M. Brio, G. M. Webb, and A. R. Zakharian, "Pareto optimality," in The Vector-Valued Maximin, V. I. Zhukovskiy and M. E. Salukvadze, Eds., vol. 193 of Mathematics in Science and Engineering, chapter 3, pp. 81-129, Academic Press, New York, NY, USA, 1994.

[68] K. K. Wong and T. K. Ho, "Dwell-time and run-time control for DC mass rapid transit railways," IET Electric Power Applications, vol. 1, no. 6, pp. 956-966, 2007. 
[69] B. Sansò and P. Girard, "Train scheduling desynchronization and power peak optimization in a subway system," in Proceedings of the IEEE/ASME Joint Railroad Conference, pp. 75-78, Baltimore, Md, USA, April 1995.

[70] K. K. Wong and T. K. Ho, "Dynamic coast control of train movement with genetic algorithm," International Journal of Systems Science, vol. 35, no. 13-14, pp. 835-846, 2004.

[71] T. Albrecht, "The influence of anticipating train driving on the dispatching process in railway conflict situations," Networks and Spatial Economics, vol. 9, no. 1, pp. 85-101, 2009.

[72] F. Corman, A. D’Ariano, D. Pacciarelli, and M. Pranzo, "Evaluation of green wave policy in real-time railway traffic management," Transportation Research C, vol. 17, no. 6, pp. 607-616, 2009.

[73] Y. Bai, T. O. Ho, and B. Mao, "Train control to reduce delays upon service disturbances at railway junctions," Journal of Transportation Systems Engineering and Information Technology, vol. 11, no. 5, pp. 114-122, 2011.

[74] W. J. Braun and D. J. Murdoch, A First Course in Statistical Programming with $R$, Cambridge University Press, Cambridge, UK, 2007.

[75] Y. Fu, Z. Gao, and K. Li, "Optimization method of energy saving train operation for railway network," Journal of Transportation Systems Engineering and Information Technology, vol. 9, no. 4, pp. 90-96, 2009.

[76] M. C. Falvo, R. Lamedica, R. Bartoni, and G. Maranzano, "Energy management in metro-transit systems: an innovative proposal toward an integrated and sustainable urban mobility system including plug-in electric vehicles," Electric Power Systems Research, vol. 81, no. 12, pp. 2127-2138, 2011.

[77] S. Robertson and J. Markham, Regenerative Braking Story, Venture Publications, Glossop, UK, 2007.

[78] M. Coto, P. Arboleya, and C. Gonzalez-Moran, “Optimization approach to unified AC/DC power flow applied to traction systems with catenary voltage constraints," International Journal of Electrical Power and Energy Systems, vol. 53, no. 1, pp. 434441, 2013.

[79] T. Suzuki, "DC power-supply system with inverting substations for traction systems using regenerative brakes," IEE Proceedings $B$, vol. 129 , no. 1 , pp. $18-26,1982$.

[80] M. B. Richardson, "Flywheel energy storage system for traction applications," in Proceedings of the International Conference on Power Electronics, Machines and Drives, Conference Publication no. 487, pp. 275-279, Bath, UK, April 2002.

[81] Y. Ding, F. Zhou, Y. Bai, and H. Liu, "Simulation algorithm for energy-efficient train following operation under automaticblock system," Journal of System Simulation, vol. 21, no. 15, pp. 4593-4597, 2009.

[82] Y. Ding, B. Mao, H. Liu, T. Wang, and X. Zhang, "Algorithm for energy-efficient train operation simulation with fixed running time," Journal of System Simulation, vol. 16, no. 10, pp. 22412244, 2004.

[83] S. Acikbas and M. T. Soylemez, "Coasting point optimisation for mass rail transit lines using artificial neural networks and genetic algorithms," IET Electric Power Applications, vol. 2, no. 3, pp. 172-182, 2008.

[84] D. Anderson and G. McNeill, Artificial Neural Networks Technology: A DACS State-of-the-Art Report, Kaman Sciences Corporation, New York, NY, USA, 1992.

[85] D. J. Livingstone, Artificial Neural Networks: Methods and Applications, Humana Press, Totowa, NJ, USA, 2008.
[86] L. Yang, K. Li, Z. Gao, and X. Li, "Optimizing trains movement on a railway network," Omega, vol. 40, no. 5, pp. 619-633, 2012.

[87] Y. Ding, H. Liu, Y. Bai, and F. Zhou, "A two-level optimization model and algorithm for energy-efficient urban train operation," Journal of Transportation Systems Engineering and Information Technology, vol. 11, no. 1, pp. 96-101, 2011.

[88] A. P. Cucala, A. Fernández, C. Sicre, and M. Domínguez, "Fuzzy optimal schedule of high speed train operation to minimize energy consumption with uncertain delays and driver's behavioral response," Engineering Applications of Artificial Intelligence, vol. 25, no. 8, pp. 1548-1557, 2012.

[89] M. Hickman, P. Mirchandani, and S. Vo, Computer-Aided Systems in Public Transport, Springer, Berlin, Germany, 2008.

[90] M. Salicrú, C. Fleurent, and J. M. Armengol, "Timetablebased operation in urban transport: run-time optimisation and improvements in the operating process," Transportation Research A, vol. 45, no. 8, pp. 721-740, 2011.

[91] Y. J. Lai and C. L. Hwang, Fuzzy Mathematical Programming: Methods and Applications, Springer, New York, NY, USA, 1995.

[92] X. Li, D. Wang, K. Li, and Z. Gao, "A green train scheduling model and fuzzy multi-objective optimization algorithm," Applied Mathematical Modelling, vol. 37, no. 4, pp. 2063-2073, 2013.

[93] W. Wang, X. Jiang, S. Xia, and Q. Cao, "Incident tree model and incident tree analysis method for quantified risk assessment: an in-depth accident study in traffic operation," Safety Science, vol. 48, no. 10, pp. 1248-1262, 2010.

[94] M. Nejlaoui, A. Houidi, Z. Affi, and L. Romdhane, "Multiobjective robust design optimization of rail vehicle moving in short radius curved tracks based on the safety and comfort criteria," Simulation Modelling Practice and Theory, vol. 30, pp. 21-34, 2013.

[95] E. Matsika, S. Ricci, P. Mortimer, N. Georgiev, and C. O’Neill, "Rail vehicles, environment, safety and security," Research in Transportation Economics, vol. 41, no. 1, pp. 43-58, 2013.

[96] G. D. Marin, G. F. Naterer, and K. Gabriel, "Rail transportation by hydrogen versus electrification-case study for Ontario Canada-I: propulsion and storage," International Journal of Hydrogen Energy, vol. 35, no. 12, pp. 6084-6096, 2010.

[97] G. D. Marin, G. F. Naterer, and K. Gabriel, "Rail transportation by hydrogen versus electrification-case study for Ontario, Canada-II: energy supply and distribution," International Journal of Hydrogen Energy, vol. 35, no. 12, pp. 6097-6107, 2010. 


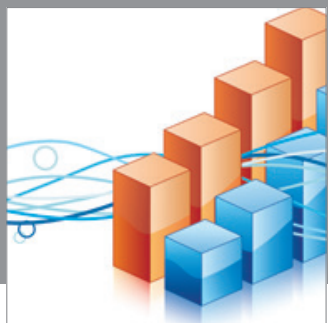

Advances in

Operations Research

mansans

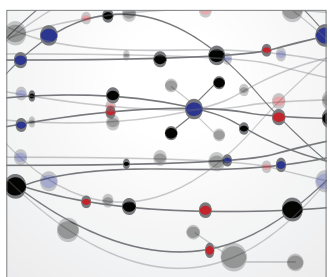

The Scientific World Journal
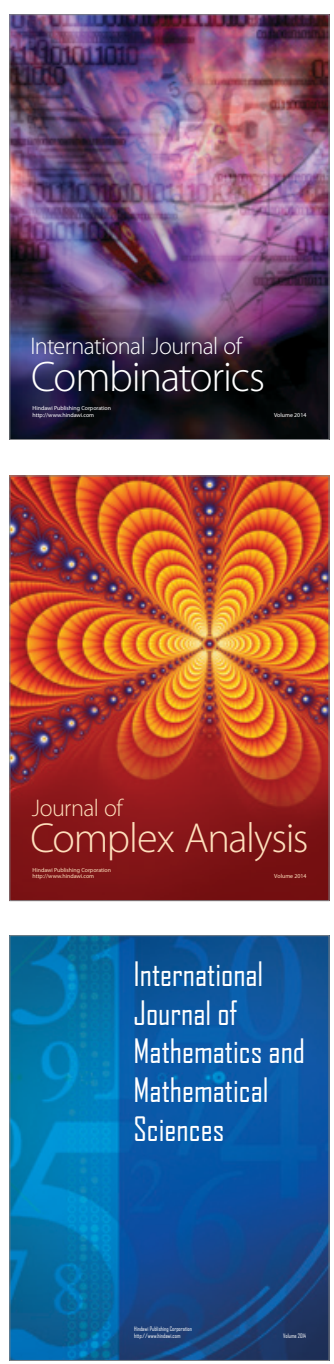
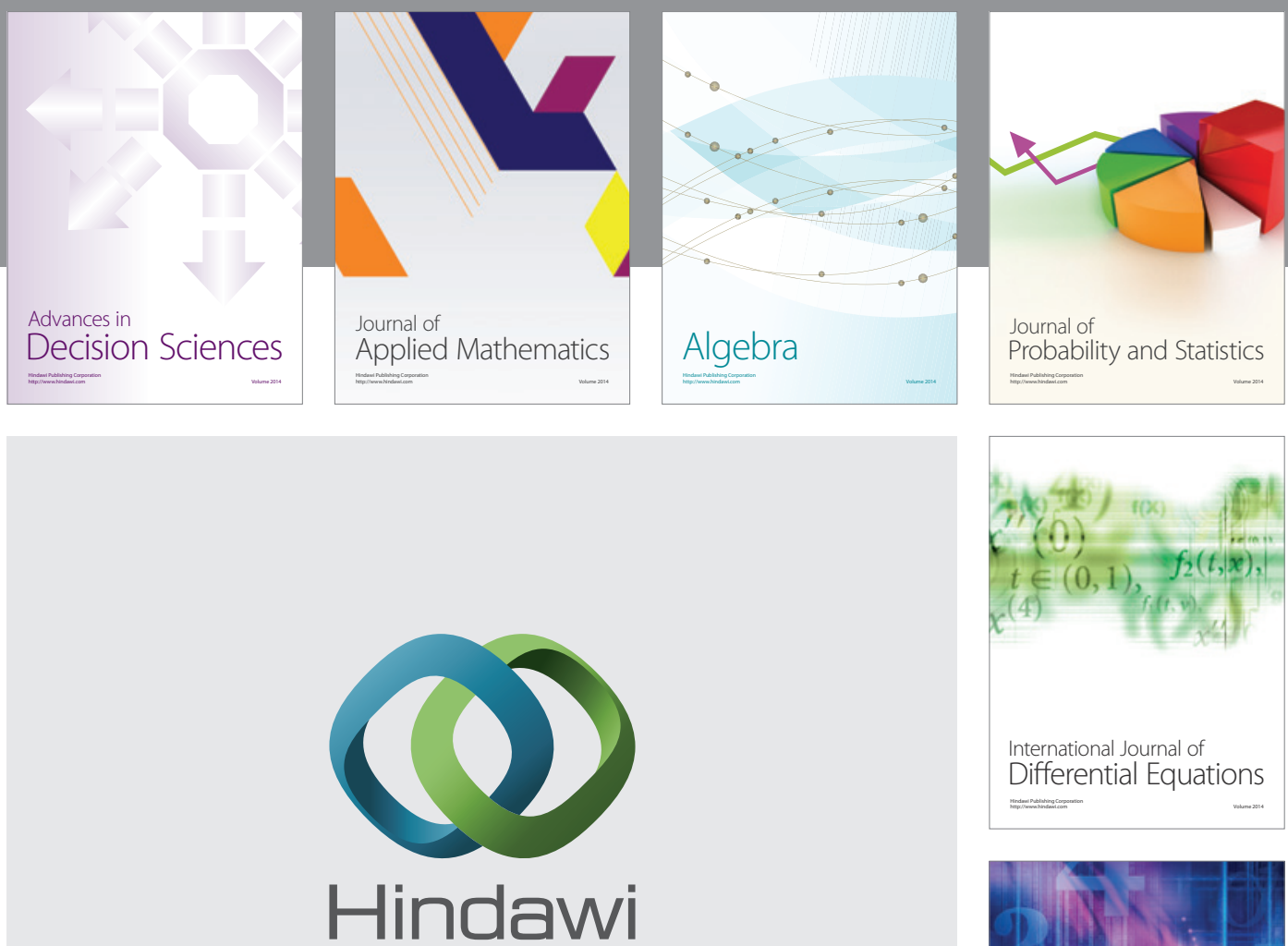

Submit your manuscripts at http://www.hindawi.com
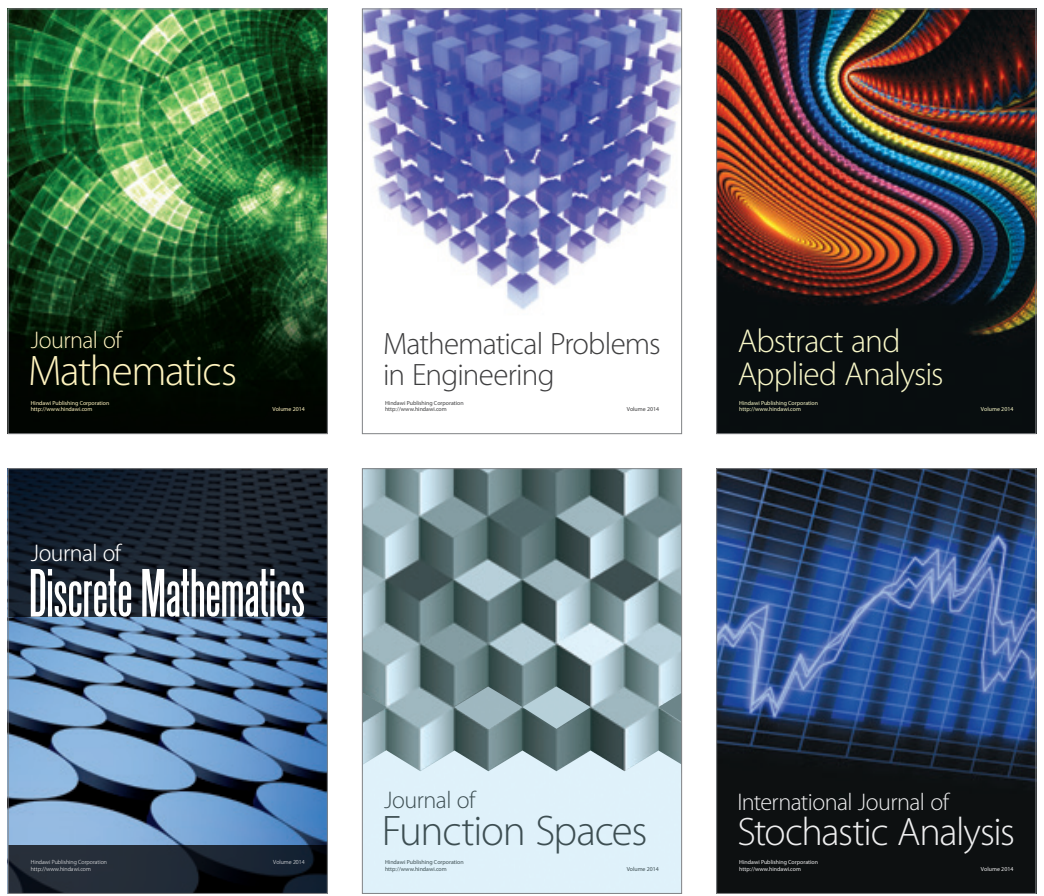

Journal of

Function Spaces

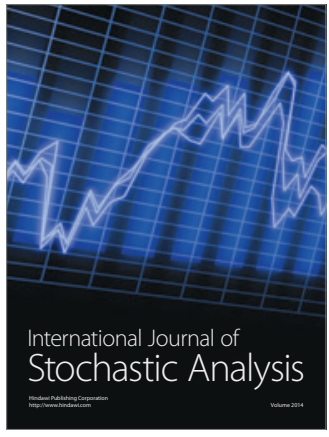

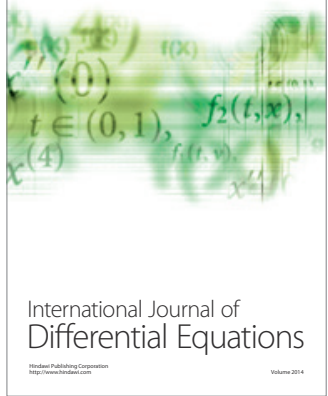
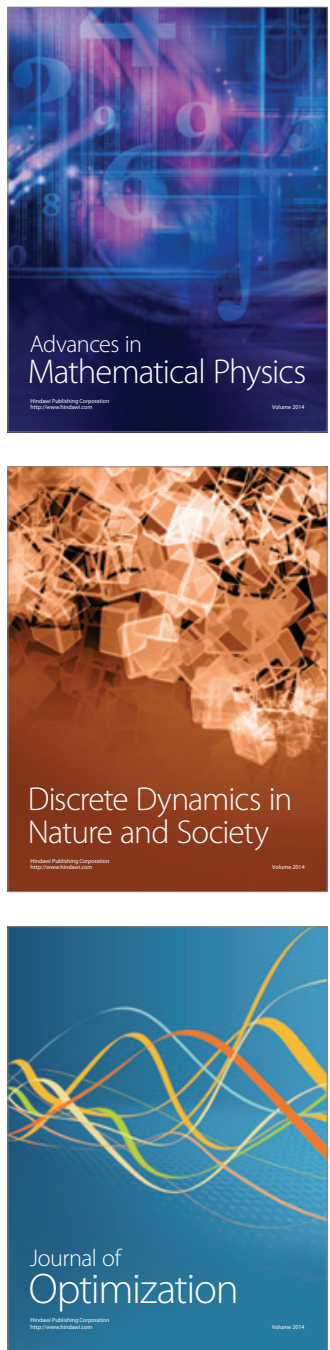